BMJ Open Sport \& Exercise Medicine

\title{
Prevalence and associated factors of insufficient physical activity among elderly people in Bangladesh: a nationally representative cross- sectional study
}

Abu Abdullah Mohammad Hanif (D) , ${ }^{1}$ Mehedi Hasan, ${ }^{1}$ Md Showkat Ali Khan, ${ }^{1}$ Md Mokbul Hossain, ${ }^{1}$ Abu Ahmed Shamim, ${ }^{1}$ Dipak Kumar Mitra, ${ }^{2}$ Moyazzam Hossaine, ${ }^{1}$ Mohammad Aman Ullah, ${ }^{3}$ Samir Kanti Sarker, ${ }^{3}$ S M Mustafizur Rahman, ${ }^{3}$ Md Mofijul Islam Bulbul, ${ }^{3}$ Malay Kanti Mridha ${ }^{1}$

\section{ABSTRACT}

Objectives Insufficient physical activity (IPA) is a crucial risk factor for non-communicable diseases (NCDs). The elderly population has a higher likelihood of suffering from NCDs. We aimed to estimate the prevalence of and factors associated with IPA among the elderly people in Bangladesh.

Methods We analysed data from the Bangladesh Food Security and Nutrition Surveillance round 2018-2019, collected from 82 rural, non-slum urban and slum clusters selected using multistage cluster sampling. IPA was defined as $<150 \mathrm{~min}$ of moderate intensity or $<75 \mathrm{~min}$ of vigorous intensity or equivalent in a typical week. The weighted prevalence of IPA was estimated by gender and across different variables. Crude and adjusted prevalence ratios were calculated using Poisson regression with robust variance.

Results The weighted prevalence of IPA among elderly people was $38.4 \%$, with a slightly higher prevalence in women $(39.7 \%$ vs $37.3 \%)$. Factors associated with higher prevalence of IPA in both sexes were-higher age, living in non-slum urban areas, unemployed or homemaker, not currently married, sedentary behaviour and self-reported hypertension. Further, $>10$ years of education, inadequate fruits and vegetable consumption, self-reported asthma and higher waist circumference among men; and higher household income and self-reported diabetes among women were associated with a higher prevalence of IPA. Conclusions IPA is highly prevalent among Bangladeshi elderly men and women. Sedentary behaviour, inadequate fruits and vegetable consumption and higher waist circumference were the modifiable factors of IPA. Evidence from this study can guide the development of appropriate interventions to promote healthy ageing in Bangladesh.

\section{INTRODUCTION}

Insufficient physical activity (IPA) is a major health concern throughout the world. The global health risk report 2009 marked IPA as one of the eight major risk factors

\section{Key messages}

What is already known

- The proportion of the elderly population is increasing in Bangladesh and other developing countries, and the health and well-being of the elderly people need to be prioritised.

- Insufficient physical activity (IPA) is a crucial risk factor of non-communicable diseases (NCDs), and the elderly population has a higher likelihood of suffering from NCDs.

What are the new findings

- IPA is highly prevalent among Bangladeshi elderly men and women. In Bangladesh, nearly two-fifths of the elderly population does not meet the World Health Organization recommendations of physical activity.

- IPA is associated with several modifiable and unmodifiable factors, including age, residence type employment status, marital status, sedentary behaviour, self-reported hypertension in both sexes of the elderly population.

responsible for three-fifths of total cardiovascular deaths and three-quarters of ischaemic heart diseases. ${ }^{1}$ IPA alone is accountable for $6 \%$ of coronary heart diseases (CHD), $7 \%$ of type 2 diabetes, $10 \%$ of both breast and colon cancer and $9 \%$ of premature mortality, that is, death before the age of 70 years. $^{2}$ About 4- 5 million premature deaths were estimated as preventable annually if the world population were more active. ${ }^{3}$ Regular physical activity has a protective effect on preventing and controlling major non-communicable diseases (NCD). ${ }^{4}$

The prevalence of IPA varies across the population. ${ }^{5}$ Studies conducted in Bangladesh and elsewhere reported a higher 
prevalence of IPA among elderly people compared with younger adults. ${ }^{6-8}$ Women are usually found to perform less physical activity than their male counterparts. ${ }^{9-11}$ Due to consistent improvement in the economy and in the health and nutrition sector, the proportion of the elderly population is increasing in Bangladesh. Bangladesh Bureau of Statistics estimated that the size of the elderly population in Bangladesh would reach 40 million, that is, $20 \%$ of the total population by the year 2050 from 12.5 million (7.5\%) in 2019. ${ }^{12}$ In Bangladesh, about $85 \%$ of elderly women and $63 \%$ of elderly men in rural areas, and $79 \%$ of elderly women and $42 \%$ of elderly men in urban areas reported four or more health problems such as eye diseases, high blood pressure, heart diseases, digestive diseases, and rheumatic pain. ${ }^{13}$ Approximately 9 out of 10 elderly people in Bangladesh are either malnourished or at risk of malnutrition. ${ }^{14}$ Accordingly, the health and well-being of the elderly population need more emphasis, and adequate physical activity is one way to improve their health.

Several factors of IPA among elderly people have been identified in Bangladesh and elsewhere. Elderly people, women, adolescents and people with disabilities are less likely to be physically active. ${ }^{10}{ }^{15}$ Reduced participation of elderly people in physical activities may be caused by their poor health conditions and disabilities. ${ }^{16}$ Education is another factor affecting participation in physical activity (PA), although the direction of association varies by country. ${ }^{917}$ Rapid and unplanned urbanisation and migration of people to urban areas are two critical factors associated with IPA in developing countries. ${ }^{18}$ Urbanisation influences several factors of IPA such as overcrowding, poverty, high crime levels, excessive traffic, lack of sidewalks, parks and other sports or recreational facilities. ${ }^{18}$ Modern transport facilities, increased use of technology for work and recreation and increasing sedentary behaviours are also associated with IPA. ${ }^{18} 19$ Other factors associated with IPA include gender, marital status, household income, demographic and cultural variation, chronic sicknesses and social support. ${ }^{16} 2021$ Identification of modifiable and non-modifiable factors of IPA is essential to design and implement programmes to improve the PA level of the elderly population.

A multisectoral action plan for the prevention and control of NCDs 2018-2025 is currently being implemented by the government of Bangladesh. ${ }^{22}$ One of the core values in the plan is life-course approach for the prevention and control of NCD. Given that PA is a key behaviour related to NCD at all stages of life, there is a need to understand the PA status among people at different life cycle stages, including the elderly population.

Evidence is limited regarding the status of PA among elderly people in Bangladesh. Moreover, the gender differentials of IPA and factors associated with IPA in the elderly women and men are important for policymaking and programme development. To minimise this knowledge gap and contribute to the policymaking for improving the health and well-being of elderly people, we aimed to estimate the prevalence of IPA separately among elderly women and men (aged $\geq 60$ years) and identify socio-demographic, behavioural and clinical factors associated with IPA.

\section{MATERIALS AND METHODS}

\section{Study design and site}

The data for this analysis was extracted from the 2018 to 2019 round of the Food Security and Nutrition Surveillance Project of Bangladesh conducted from October 2018 through October 2019. The survey was designed to generate national and regional estimates of numerous nutritional and health-related indicators of six population groups, including the elderly population (aged $\geq 60$ years). The study participants were enrolled from rural, non-slum urban and slum areas in all eight administrative divisions of Bangladesh. Details of study design and methods are available elsewhere. ${ }^{23-25}$

\section{Sample size and sampling techniques}

We calculated a sample size of 62 elderly people from each and a total of 5580 elderly people from 90 randomly selected clusters. We used a five-stage cluster sampling technique for rural and a three-stage cluster sampling technique for non-slum urban and slum areas to select the clusters. The participants could be enrolled from 82 clusters ( 57 rural, 15 non-slum urban and 10 slums). One cluster was common for non-slum urban and slum areas, and seven clusters were dropped due to administrative and financial constraints. Further details on sample size calculation, cluster selection and participant enrolment were published elsewhere. ${ }^{25}$ Figure 1 demonstrates the process of selecting the study participants for this analysis.

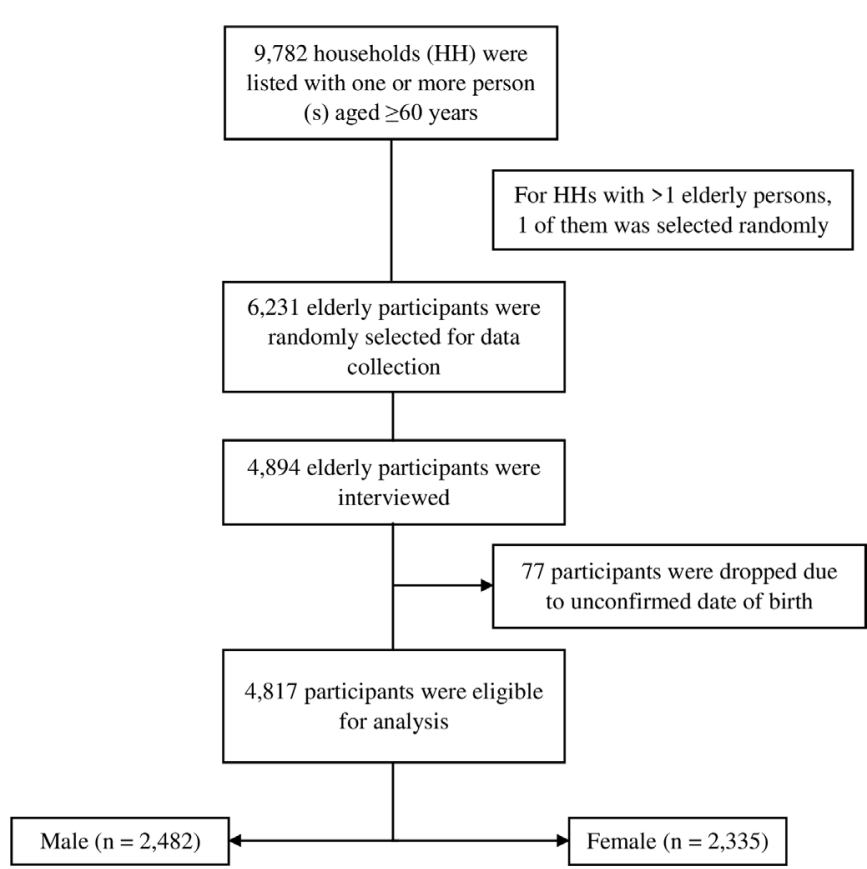

Figure 1 Flowchart of study participants selection and enrolment. 
Data collection and quality control

A structured questionnaire, developed in English, and translated to Bengali, was used. Data were collected using face-to-face interviews, and anthropometric measurements were taken at the respondents' residences. Data were directly entered into a digital data collection platform named SurveyCTO (Dobility) using tablet computers. The questionnaire was field-tested, modified and research assistants were retrained based on field-test findings. The data collection supervisors observed 5\% of the interviews and reinterviewed another $5 \%$ of the randomly selected study participants within two working days from initial data collection. Data quality was also monitored through periodic interim analyses. More details on data collection and anthropometric measurements have been described elsewhere. ${ }^{25}$

\section{Outcome variable}

IPA was estimated following the 2010 WHO guidelines on PA. According to the guideline, persons aged 18-64 years, and $\geq 65$ years, are required to perform at least $150 \mathrm{~min}$ of moderate intensity, or $75 \mathrm{~min}$ of vigorous intensity or an equivalent combination of PA in a week. ${ }^{26}$ We collected PA data using a modified version of the Global Physical Activity Questionnaire (GPAQ) . GPAQ has been validated in the Bangladeshi population. ${ }^{27}$ GPAQ has been used in many studies conducted in
Bangladesh, especially in different rounds of the national NCD risk factors surveys conducted in regular intervals. ${ }^{67}$ We combined all the vigorous-intensity activities in one and all moderate-intensity activities in another question to reduce interview time. We separately calculated the sum of weekly vigorous-intensity and moderate-intensity activities and added them together, multiplying vigorous activity by 2 , as $1 \mathrm{~min}$ of vigorous-intensity activity is equivalent to $2 \mathrm{~min}$ of moderate-intensity activity. ${ }^{26}$ The persons with $<150 \mathrm{~min}$ of $\mathrm{PA}$ in a week were considered insufficiently physically active.

\section{Explanatory variables}

We selected a list of variables based on the literature review and data availability in our survey. We included several social-demographic, behavioural, clinical and anthropometric variables as explanatory variables in the analysis. Selected variables are detailed in table 1 . Details on measurement approaches of those variables, especially the procedures of anthropometric measurements, were published elsewhere. ${ }^{2528}$

\section{Statistical analysis}

We used Stata V.16.0 (StataCorp) for data management and analysis. We estimated the weighted prevalence of IPA with a 95\% confidence interval (CI) for both sexes. We estimated unadjusted and adjusted prevalence ratios

Table 1 List of the outcome and explanatory variables included in the analysis

Variables Category

Outcome variable:

Insufficient physical activity

No=0 ( $\geq 150$ of moderate-intensity or $\geq 75$ min of vigorous-intensity physical activity or a combination of both in a week);

Yes $=1$ ( $<150$ of moderate-intensity or $\geq 75$ min of vigorous-intensity physical activity or a combination of both in a week)

\begin{tabular}{ll}
\hline Explanatory variables: & \\
\hline Age in years & Male/female \\
\hline Sex & Rural/non-slum urban/slum \\
\hline Place of residence & Mymensingh/Barishal/Chattogram/Dhaka/Khulna/Rajshahi/Rangpur/Sylhet \\
\hline Divisions (regions) & No formal education/1-5years/ 6-10years/>10 years \\
\hline Educational status & Working/unemployed or homemaker \\
\hline Occupation & Below median/median or above \\
\hline Household income & Currently married/others (never married, divorced, separated, widowed) \\
\hline Marital status & Muslim/others (Buddhists, Christians, Hindu and all others) \\
\hline Religion & $\leq 7$ hours in a typical day/ $>7$ hour in a typical day \\
\hline Sedentary time & $\geq 5$ servings per day/ $<5$ servings per day \\
\hline Fruits and vegetable consumption & No/yes \\
\hline Self-reported hypertension* & No/yes \\
\hline Self-reported diabetes* & No/yes \\
\hline Self-reported heart diseases* & No/yes \\
\hline Self-reported asthma* & Male: $<90 \mathrm{~cm}$ or female: $<80 \mathrm{~cm} / \mathrm{male:} \geq 90 \mathrm{~cm}$ or female: $\geq 80 \mathrm{~cm}$ \\
\hline Waist circumference &
\end{tabular}

*'Yes', if any trained healthcare provider ever told the study participant that they have the disease(s) and 'no' if otherwise. 
Open access

Table 2 Background characteristics of the study population

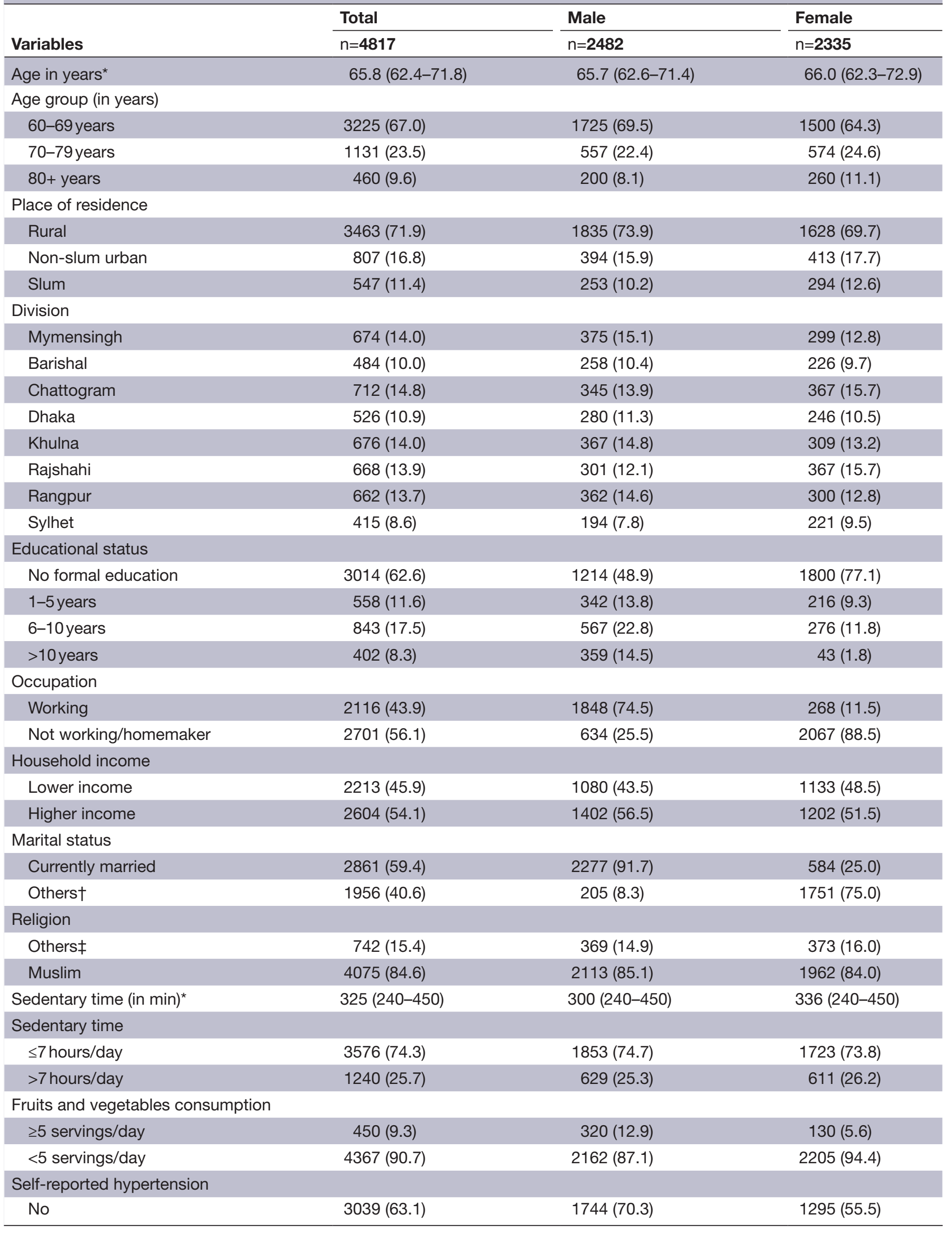


Table 2 Continued

\begin{tabular}{|c|c|c|c|}
\hline & Total & Male & Female \\
\hline Variables & $n=4817$ & $n=2482$ & $n=2335$ \\
\hline Yes & 1778 (36.9) & $738(29.7)$ & $1040(44.5)$ \\
\hline \multicolumn{4}{|l|}{ Self-reported diabetes } \\
\hline No & 4238 (88.0) & 2212 (89.1) & 2026 (86.8) \\
\hline Yes & $579(12.0)$ & $270(10.9)$ & $309(13.2)$ \\
\hline \multicolumn{4}{|l|}{ Self-reported heart disease } \\
\hline No & $3989(82.8)$ & $2051(82.6)$ & $1938(83.0)$ \\
\hline Yes & $828(17.2)$ & $431(17.4)$ & $397(17.0)$ \\
\hline \multicolumn{4}{|l|}{ Self-reported asthma } \\
\hline No & $4097(85.1)$ & 2079 (83.8) & 2018 (86.4) \\
\hline Yes & $720(14.9)$ & $403(16.2)$ & $317(13.6)$ \\
\hline Waist circumference ${ }^{\star}$ & $79.0(71.4-87.9)$ & $81.0(73.3-89.1)$ & $77.1(69.1-86.4)$ \\
\hline \multicolumn{4}{|l|}{ Waist circumference (category) } \\
\hline Male: $<90 \mathrm{~cm} /$ female: $<80 \mathrm{~cm}$ & $3227(68.5)$ & $1887(77.1)$ & $1340(59.1)$ \\
\hline Male: $\geq 90 \mathrm{~cm} /$ female: $\geq 80 \mathrm{~cm}$ & $1487(31.5)$ & $560(22.9)$ & 927 (40.9) \\
\hline
\end{tabular}

${ }^{*}$ Continuous variables (all others are categorical variables): Data are presented as column percentages, $\mathrm{n}(\%)$ for categorical variables and as median (IQR) for continuous variables.

†Never married, widows, divorced and separated.

łHindu, Christian, Buddhist and others.

(PR) of IPA separately for both sexes using Poisson regression with robust variance as the prevalence of IPA was greater than $10 \% .^{29}$ Several studies have demonstrated that, compared with PR, ORs overestimate the magnitude of association in cross-sectional studies, especially when the outcome is not a rare event. ${ }^{30}$ Besides, Poisson regression with robust variance effectively avoids convergence difficulty, which commonly occurs in log-binomial regression, and the prevalence ratios are straightforward to interpret. ${ }^{31}$ We selected the variables with a $p$ value $\leq 0.2$ in unadjusted analysis and included them in the adjusted analysis. ${ }^{32}$ We checked variance inflation factors to assess multicollinearity among the variables. The factors with a p-value $<0.05$ were considered statistically significant.

\section{RESULTS}

\section{Characteristics of the study participants}

A total of 4894 participants aged $\geq 60$ years were enrolled. However, we dropped 77 participants with unconfirmed dates of birth. We analysed data of 4817 participants with a median age of 65.8 (IQR: 62.4-71.8) years. About $49 \%$ of the participants were women, $72 \%$ were from rural areas and $85 \%$ were Muslims. About three-fifths of the participants had no formal education, and $56 \%$ were either homemakers or unemployed. More than twothirds of the participants were not currently married, with fewer married women $(25 \%)$ than their male counterparts (92\%). One in every four participants reported higher sedentary time, and 9 out of 10 did not consume adequate fruits and vegetable. Self-reported hypertension, diabetes, heart diseases and asthma were reported by about $37 \%, 12 \%, 17 \%$ and $15 \%$ of the participants, respectively. One-third of the participants had a higher waist circumference (table 2).

\section{Prevalence of IPA}

The prevalence of IPA among elderly people was $38.4 \%$, with a minimal difference between men and women. The prevalence was about 1.5 times higher among those aged $70-79$ years $(48.9 \%)$ and double among those aged $\geq 80+$ years $(71.3 \%)$, compared with those aged $60-69$ years (29.2\%). The women aged 60-69 years and 70-79 years had a higher prevalence of IPA than their male counterparts but the women aged $\geq 80$ years had a lower prevalence of IPA than the men in the same age group. Compared with those living in rural and slum areas, the prevalence of IPA in elderly people living in non-slum urban areas was almost double. Among the divisions, the highest prevalence of IPA was in Barishal (56.0\%), and the lowest was in Mymensingh (23.3\%). The elderly people with higher education had a higher prevalence of IPA. The participants with higher sedentary time, selfreported $\mathrm{NCD}(\mathrm{s})$ and higher waist circumference had a higher prevalence of IPA (table 3).

\section{Factors associated with IPA}

Tables 4 and 5 displayed the results of the crude and adjusted Poisson regression analysis with robust variances. From the adjusted analysis among the male participants; higher age groups (adjusted prevalence ratio (APR): 1.21, 95\% CI: 1.10 to 1.34 ) for $70-79$ years and (APR: 1.59 , $95 \%$ CI: 1.41 to 1.79 ) for $\geq 80$ years); living in non-slum urban areas (APR: $1.46,95 \%$ CI: 1.31 to 1.63 ) and slum (APR: 1.49 , 95\% CI: 1.32 to 1.69 ); >10 years of education 
Table 3 Prevalence of insufficient physical activity across the strata of the background characteristics of the study population by gender (weighted)

\begin{tabular}{|c|c|c|c|}
\hline & Overall $(n=4817)$ & Male $(n=2482)$ & Female $(n=2335)$ \\
\hline Variables & Prevalence $(95 \% \mathrm{Cl})$ & Prevalence $(95 \% \mathrm{Cl})$ & Prevalence $(95 \% \mathrm{Cl})$ \\
\hline Overall & 38.4 (34.0 to 43.0$)$ & 37.3 (32.3 to 42.4 ) & 39.7 (34.9 to 44.7 ) \\
\hline \multicolumn{4}{|l|}{ Age group (in years) } \\
\hline 60-69years & 29.2 (24.8 to 34.0$)$ & 28.2 (24.0 to 32.7 ) & 30.3 (24.8 to 36.4$)$ \\
\hline 70-79years & 48.9 (42.7 to 55.1$)$ & 46.6 (36.8 to 56.8$)$ & 51.8 (45.3 to 58.2 ) \\
\hline $80+$ years & 71.3 (63.3 to 78.2 ) & 74.2 (63.7 to 82.6$)$ & 68.8 (58.9 to 77.2 ) \\
\hline \multicolumn{4}{|l|}{ Place of residence } \\
\hline Rural & 37.8 (33.3 to 42.4$)$ & 36.5 (31.6 to 41.8$)$ & 39.1 (34.2 to 44.2$)$ \\
\hline Non-slum urban & 78.9 (50.0 to 93.3$)$ & 79.5 (49.7 to 93.8$)$ & 78.2 (50.2 to 92.8$)$ \\
\hline Slum & 38.6 (26.5 to 52.4$)$ & 44.7 (31.7 to 58.4$)$ & 32.4 (16.5 to 53.7$)$ \\
\hline \multicolumn{4}{|l|}{ Division } \\
\hline Mymensingh & 23.3 (18.4 to 29.1$)$ & 24.8 (15.9 to 36.6$)$ & 21.1 (11.6 to 35.2) \\
\hline Barishal & 56.0 (42.0 to 69.0$)$ & 56.4 (35.2 to 75.5$)$ & 55.5 (47.0 to 63.7$)$ \\
\hline Chattogram & 54.0 (41.5 to 66.0 ) & 48.6 (31.0 to 66.6$)$ & 58.6 (49.1 to 67.5$)$ \\
\hline Dhaka & 42.9 (30.8 to 55.8$)$ & 40.3 (27.5 to 54.6$)$ & 45.9 (27.6 to 65.3$)$ \\
\hline Khulna & 33.2 (26.3 to 40.8 ) & 29.3 (23.3 to 36.0 ) & 37.8 (28.9 to 47.5$)$ \\
\hline Rajshahi & 39.6 (26.9 to 53.9 ) & 40.6 (24.3 to 59.3$)$ & 38.6 (29.3 to 48.7$)$ \\
\hline Rangpur & 32.4 (22.7 to 43.9$)$ & 34.5 (25.3 to 45.1$)$ & 30.1 (17.7 to 46.2$)$ \\
\hline Sylhet & 37.1 (32.8 to 41.7 ) & 38.8 (28.0 to 50.8 ) & 35.5 (26.3 to 46.0$)$ \\
\hline \multicolumn{4}{|l|}{ Educational status } \\
\hline No formal education & 38.2 (33.3 to 43.3 ) & 33.6 (27.8 to 39.9 ) & 41.4 (36.4 to 46.7$)$ \\
\hline $1-5$ years & 31.2 (24.8 to 38.4$)$ & $31.0(23.7$ to 39.4$)$ & 31.5 (23.2 to 41.1$)$ \\
\hline $6-10$ years & 40.5 (33.4 to 48.0 ) & 42.9 (35.5 to 50.5$)$ & 34.3 (23.0 to 47.7 ) \\
\hline$>10$ years & 51.3 (43.0 to 59.6 ) & 52.0 (43.1 to 60.7$)$ & 42.8 (24.3 to 63.5$)$ \\
\hline \multicolumn{4}{|l|}{ Occupation } \\
\hline Working & 26.6 (21.0 to 33.1$)$ & 24.7 (20.0 to 30.2$)$ & 44.5 (28.4 to 61.9$)$ \\
\hline Not working/homemaker & 47.2 (42.6 to 51.9$)$ & 72.7 (64.2 to 79.8$)$ & 39.2 (34.8 to 43.8$)$ \\
\hline \multicolumn{4}{|l|}{ Household income } \\
\hline Lower income & 36.0 (30.0 to 42.5$)$ & 36.8 (30.0 to 44.2$)$ & 35.1 (28.9 to 41.8$)$ \\
\hline Higher income & 41.0 (36.2 to 45.9$)$ & 37.7 (32.4 to 43.2$)$ & 44.8 (38.5 to 51.3$)$ \\
\hline \multicolumn{4}{|l|}{ Marital status } \\
\hline Currently married & 32.2 (27.3 to 37.5$)$ & 35.3 (30.2 to 40.7$)$ & 24.1 (17.8 to 31.8$)$ \\
\hline Others* & 51.7 (47.3 to 56.0$)$ & 68.9 (57.3 to 78.5$)$ & 49.8 (44.9 to 54.7$)$ \\
\hline \multicolumn{4}{|l|}{ Religion } \\
\hline Others $†$ & 34.4 (29.4 to 39.8$)$ & 32.0 (25.8 to 38.8$)$ & 36.9 (30.0 to 44.4$)$ \\
\hline Muslim & 39.2 (34.2 to 44.4$)$ & 38.3 (32.8 to 44.0$)$ & 40.2 (34.7 to 46.0$)$ \\
\hline \multicolumn{4}{|l|}{ Sedentary time } \\
\hline$\leq 7$ hours/day & 31.9 (27.3 to 37.0$)$ & 30.2 (25.2 to 35.6$)$ & 33.8 (28.5 to 39.6$)$ \\
\hline$>7$ hours/day & 58.0 (51.6 to 64.2$)$ & 58.6 (51.6 to 65.3$)$ & 57.4 (47.6 to 66.6$)$ \\
\hline \multicolumn{4}{|c|}{ Fruits and vegetables consumption } \\
\hline$\geq 5$ servings/day & 29.2 (21.0 to 39.0$)$ & 30.4 (21.5 to 41.1$)$ & 26.2 (14.7 to 42.4$)$ \\
\hline$<5$ servings/day & 39.4 (34.7 to 44.2$)$ & $38.3(32.7$ to 44.1$)$ & 40.5 (35.7 to 45.6$)$ \\
\hline \multicolumn{4}{|l|}{ Self-reported hypertension } \\
\hline No & 33.7 (29.2 to 38.5$)$ & 32.1 (26.7 to 38.1$)$ & 35.9 (30.5 to 41.8$)$ \\
\hline
\end{tabular}


Table 3 Continued

\begin{tabular}{|c|c|c|c|}
\hline \multirow[b]{2}{*}{ Variables } & \multirow{2}{*}{$\begin{array}{l}\text { Overall }(\mathrm{n}=4817) \\
\text { Prevalence }(95 \% \mathrm{Cl})\end{array}$} & \multirow{2}{*}{$\begin{array}{l}\text { Male }(\mathrm{n}=\mathbf{2 4 8 2}) \\
\text { Prevalence }(95 \% \mathrm{Cl})\end{array}$} & \multirow{2}{*}{$\begin{array}{l}\text { Female }(n=2335) \\
\text { Prevalence }(95 \% \mathrm{Cl})\end{array}$} \\
\hline & & & \\
\hline Yes & 46.8 (41.6 to 52.0$)$ & 50.0 (43.7 to 56.3$)$ & 44.4 (39.0 to 50.0$)$ \\
\hline \multicolumn{4}{|l|}{ Self-reported diabetes } \\
\hline No & 37.3 (32.9 to 41.8 ) & 36.5 (31.4 to 41.9$)$ & 38.2 (33.4 to 43.2 ) \\
\hline Yes & 49.9 (41.6 to 58.3$)$ & 46.6 (35.7 to 57.9$)$ & 52.6 (42.7 to 62.2$)$ \\
\hline \multicolumn{4}{|l|}{ Self-reported heart disease } \\
\hline No & 36.3 (32.0 to 40.9$)$ & 34.6 (29.9 to 39.6$)$ & 38.2 (33.2 to 43.4$)$ \\
\hline Yes & 49.3 (43.0 to 55.6$)$ & 50.0 (42.0 to 58.1$)$ & 48.3 (40.6 to 56.1$)$ \\
\hline \multicolumn{4}{|l|}{ Self-reported asthma } \\
\hline No & 35.9 (31.6 to 40.4$)$ & 34.3 (29.2 to 39.8$)$ & 37.5 (32.8 to 42.5$)$ \\
\hline Yes & 53.7 (46.9 to 60.3 ) & 52.9 (45.5 to 60.1$)$ & 54.8 (46.5 to 62.8$)$ \\
\hline \multicolumn{4}{|l|}{ Waist circumference } \\
\hline Male: $<90 \mathrm{~cm} /$ female: $<80 \mathrm{~cm}$ & 35.2 (30.3 to 40.4$)$ & 34.4 (28.7 to 40.6$)$ & 36.3 (30.7 to 42.3$)$ \\
\hline Male: $\geq 90 \mathrm{~cm} /$ female: $\geq 80 \mathrm{~cm}$ & 43.6 (38.8 to 48.6$)$ & 45.9 (39.4 to 52.5$)$ & 42.3 (36.8 to 48.0$)$ \\
\hline
\end{tabular}

*Never married, widows, divorced and separated.

†Hindu, Christian, Buddhist and others.

(APR: $1.21,95 \%$ CI: 1.06 to 1.37 ); being unemployed or homemaker (APR: 1.91, 95\% CI: 1.74 to 2.09); being not currently married (APR: 1.14, 95\% CI: 1.02 to 1.28); higher sedentary time (APR: 1.37, 95\% CI: 1.25 to 1.50 ); inadequate fruits and vegetable consumption (APR: 1.25, $95 \%$ CI: 1.06 to 1.48); self-reported hypertension (APR: 1.15, $95 \%$ CI: 1.05 to 1.26 ); self-reported asthma (APR: 1.13, 95\% CI: 1.03 to 1.24 ); and higher waist circumference (APR: $1.20,95 \%$ CI: 1.08 to 1.33 ) were associated with higher prevalence of IPA.

From the adjusted analysis among female participants; higher age groups (APR: 1.39, 95\% CI: 1.26 to 1.54 for 70-79 years) and (APR: $1.76,95 \%$ CI: 1.57 to 1.97 for $\geq 80$ years); living in non-slum urban areas (APR: $1.33,95 \%$ CI: 1.19 to 1.48 ); being unemployed or homemaker (APR: 1.33, 95\% CI: 1.12 to 1.58); higher household income (APR: $1.12,95 \%$ CI: 1.02 to 1.23 ); being not currently married (APR: 1.40, 95\% CI: 1.22 to 1.60 ); sedentary time $>7$ hours/day (APR: $1.40,95 \%$ CI: 1.28 to 1.53 ); selfreported hypertension (APR: 1.18, 95\% CI: 1.05 to 1.25); and self-reported diabetes (APR: 1.18, 95\% CI: 1.05 to 1.33) were associated with higher prevalence of IPA.

\section{DISCUSSION}

\section{Summary of the study findings}

In Bangladesh, nearly two-fifths of the elderly population does not meet the WHO PA recommendations. The overall prevalence of IPA among women and men was similar. Besides, the prevalence of IPA was higher among the higher age groups, residents of non-slum urban areas, educated men, people with self-reported NCDs (hypertension, diabetes, heart diseases and asthma) and those with higher waist circumferences. The study also revealed several socio-demographic, behavioural, clinical and anthropometric factors associated with IPA.
Among these factors, higher age, residence in non-slum urban areas, being unemployed or homemaker, not being currently married, sedentary behaviour, and selfreported hypertension were associated with IPA in both sexes. Besides, higher education, inadequate fruits and vegetable consumption, self-reported asthma and higher waist circumference among men and higher household income and self-reported diabetes among women were associated with IPA.

\section{Prevalence of IPA in the elderly population}

In our study, the overall weighted prevalence of IPA among elderly people was $38.4 \%$. However, the prevalence of IPA observed in our study was higher than the prevalence of IPA (23.1\%) among those aged 55-69 years, reported by the Bangladesh NCD risk factors survey 2018. ${ }^{6}$ In the NCD risk factors surveys using the WHO STEPwise Approach to NCD Risk Factor Surveillance (STEPS) method, participants are usually between 18-69 years of age. Accordingly, data are relatively unavailable for elderly people aged 70 years and above. Only 1 out of 30 studies included in a recently published systematic review had data on the PA of the elderly population. ${ }^{33}$ However, we could not compare our findings with the findings of that study as the researchers did not follow any specific method to measure IPA. In Bangladesh, life expectancy at birth has increased from 66 years in 2001 to 72.6 years in $2019 .^{34}$ As elderly population is more vulnerable to NCDs and IPA is one of the key risk factors of NCDs, periodic data collection of PA among elderly people is crucial.

Though there is limited evidence of IPA among the elderly population in Bangladesh, we could compare our findings with the prevalence of IPA among the elderly population of similar age groups in the recent WHO 
Open access

Table 4 Crude prevalence ratios (CPR) of the factors of insufficient physical activity for men and women*

\begin{tabular}{|c|c|c|c|c|}
\hline \multirow[b]{2}{*}{ Variables } & \multicolumn{2}{|l|}{ Male } & \multicolumn{2}{|l|}{ Female } \\
\hline & CPR $(95 \% \mathrm{Cl})$ & $P$ value & CPR $(95 \% \mathrm{Cl})$ & $P$ value \\
\hline \multicolumn{5}{|l|}{ Age group (in years) } \\
\hline 60-69years & Ref. & & Ref. & \\
\hline $70-79$ years & 1.48 (1.34 to 1.64$)$ & $<0.001$ & 1.55 (1.40 to 1.71$)$ & $<0.001$ \\
\hline $80+$ years & 2.21 (2.00 to 2.44$)$ & $<0.001$ & 1.95 (1.77 to 2.16$)$ & $<0.001$ \\
\hline \multicolumn{5}{|l|}{ Place of residence } \\
\hline Rural & Ref. & & Ref. & \\
\hline Non-slum urban & 1.84 (1.67 to 2.02 ) & $<0.001$ & 1.55 (1.41 to 1.7$)$ & $<0.001$ \\
\hline Slum & 1.58 (1.40 to 1.80$)$ & $<0.001$ & 1.10 (0.95 to 1.26$)$ & 0.198 \\
\hline \multicolumn{5}{|l|}{ Educational status } \\
\hline No formal education & Ref. & & Ref. & \\
\hline $1-5$ years & 1.05 (0.90 to 1.22$)$ & 0.536 & 0.93 (0.79 to 1.10$)$ & 0.395 \\
\hline $6-10$ years & 1.22 (1.08 to 1.37$)$ & 0.001 & $1.13(1.00$ to 1.29$)$ & 0.055 \\
\hline$>10$ years & $1.58(1.41$ to 1.77$)$ & $<0.001$ & 1.30 (1.00 to 1.68$)$ & 0.048 \\
\hline \multicolumn{5}{|l|}{ Occupation } \\
\hline Working & Ref. & & Ref. & \\
\hline Not working/homemaker & 2.45 (2.26 to 2.66$)$ & $<0.001$ & 1.35 (1.14 to 1.60$)$ & 0.001 \\
\hline \multicolumn{5}{|l|}{ Household income } \\
\hline Lower income & Ref. & & Ref. & \\
\hline Higher income & 1.06 (0.96 to 1.16$)$ & 0.238 & 1.27 (1.16 to 1.39$)$ & $<0.001$ \\
\hline \multicolumn{5}{|l|}{ Marital status } \\
\hline Currently married & Ref. & & Ref. & \\
\hline Others ${ }^{\prime}$ & 1.71 (1.54 to 1.90$)$ & $<0.001$ & 1.71 (1.50 to 1.96$)$ & $<0.001$ \\
\hline \multicolumn{5}{|l|}{ Religion } \\
\hline Othersł & Ref. & & Ref. & \\
\hline Muslim & $1.02(0.90$ to 1.17$)$ & 0.737 & 1.11 (0.98 to 1.26$)$ & 0.110 \\
\hline \multicolumn{5}{|l|}{ Sedentary time } \\
\hline$\leq 7$ hours/day & Ref. & & Ref. & \\
\hline$>7$ hours/day & 1.73 (1.59 to 1.89$)$ & $<0.001$ & 1.54 (1.42 to 1.68$)$ & $<0.001$ \\
\hline \multicolumn{5}{|c|}{ Fruits and vegetables consumption } \\
\hline$\geq 5$ servings/day & Ref. & & Ref. & \\
\hline$<5$ servings/day & 1.54 (1.29 to 1.84$)$ & $<0.001$ & $1.43(1.11$ to 1.84$)$ & 0.006 \\
\hline \multicolumn{5}{|l|}{ Self-reported hypertension } \\
\hline No & Ref. & & Ref. & \\
\hline Yes & 1.46 (1.34 to 1.60$)$ & $<0.001$ & 1.27 (1.16 to 1.39$)$ & $<0.001$ \\
\hline \multicolumn{5}{|l|}{ Self-reported diabetes } \\
\hline No & Ref. & & Ref. & \\
\hline Yes & 1.41 (1.26 to 1.58$)$ & $<0.001$ & $1.36(1.22$ to 1.51$)$ & $<0.001$ \\
\hline \multicolumn{5}{|l|}{ Self-reported heart disease } \\
\hline No & Ref. & & Ref. & \\
\hline Yes & 1.35 (1.22 to 1.50$)$ & $<0.001$ & 1.25 (1.13 to 1.38$)$ & $<0.001$ \\
\hline \multicolumn{5}{|l|}{ Self-reported asthma } \\
\hline No & Ref. & & Ref. & \\
\hline Yes & 1.39 (1.26 to 1.54$)$ & $<0.001$ & $1.20(1.07$ to 1.34$)$ & 0.002 \\
\hline
\end{tabular}




\begin{tabular}{|c|c|c|c|c|}
\hline \multirow[b]{2}{*}{ Variables } & \multicolumn{2}{|l|}{ Male } & \multicolumn{2}{|l|}{ Female } \\
\hline & CPR $(95 \% \mathrm{Cl})$ & $P$ value & CPR $(95 \% \mathrm{Cl})$ & $P$ value \\
\hline Male: $<90 \mathrm{~cm} /$ female: $<80 \mathrm{~cm}$ & Ref. & & Ref. & \\
\hline Male: $\geq 90 \mathrm{~cm} /$ female: $\geq 80 \mathrm{~cm}$ & 1.48 (1.35 to 1.63$)$ & $<0.001$ & 1.20 (1.10 to 1.32$)$ & $<0.001$ \\
\hline
\end{tabular}

*The outcome variable of Poisson regression analysis was insufficient physical activity $(\geq 150$ of physical activity per week=0, $<150$ min of physical activity per week=1).

†Never married, widows, divorced and separated.

$\ddagger$ Hindu, Christian, Buddhist and others.

NA, not applicable; Ref, reference category.

STEPS survey conducted in South Asian countries. The prevalence of IPA in our study was found higher than that in Afghanistan (34.9\%; 45-69 years), Nepal (11.6\%; 55-69 years), Bhutan (6.4\%; 40-69 years), Sri Lanka (36.0\%; 60-69 years) and lower than the prevalence of IPA among elderly people in Kerala, India (61.4\%; 56-65 years), Tamil Nadu, India (53.5\%; 60-64 years), Pakistan (52.9\%; 60-69 years) and Maldives $(45.3 \%$ in men and $47.5 \%$ in women; $55-64$ years) ${ }^{35-42}$ However, our reported prevalence is still lower than the prevalence of IPA among elderly people in some western countries, such as in the USA $\left(64,2 \% ; 65+\right.$ years ${ }^{43}$ and Australia (69\% in men and $75 \%$ in women; $65+$ years). ${ }^{44}$ In the UK, $40 \%$ of the people aged $55-74$ years and $62 \%$ of those aged $75+$ years were physically inactive. ${ }^{45} \mathrm{~A}$ crosssectional analysis of the Wave-4 data of the Survey of Health, Ageing, and Retirement in Europe database of the people aged 55+ years from 19 countries of Europe and Israel reported the prevalence of IPA from $4.9 \%$ (Sweden) to $29 \%$ (Portugal). ${ }^{46}$ Globally, $17 \%$ to $97.6 \%$ of the elderly people do not meet the recommended PA requirement, according to a systematic review conducted by Sun $e t a l^{10}$ The prevalence of IPA among the countries might vary due to the differences in study settings, age groups, study timeline, socio-demographic and other factors.

\section{Factors associated with IPA among elderly people}

The findings of our study revealed an association between age and IPA, and the prevalence of IPA was higher among the higher age groups in both sexes. This finding corroborates with several other studies conducted in Bangladesh and elsewhere. ${ }^{68}$ A systematic review of PA among elderly people also found a similar relationship between age and physical inactivity. ${ }^{10}$ Elderly people in higher age groups often suffer from different NCDs resulting in limited mobility and less participation in PA. ${ }^{47}$

In our study, elderly people living in urban areas were less physically active than their rural counterparts. Several studies included in a systematic review corroborated these findings. ${ }^{33}$ In Bangladesh, urban people are confined indoors due to a lack of outdoor recreational space and security. ${ }^{33}$ As Bangladesh is experiencing rapid urbanisation, and one in every three people live in an urban area, ${ }^{48}$ special consideration should be given to the urban people while designing public health programmes aimed to improve PA.

In contrast to the global findings, our analysis revealed that elderly men with relatively higher education are more likely to be physically inactive. ${ }^{16}{ }^{17}$ A study conducted in nine rural sites of five South-East Asian countries, including Bangladesh, reported similar findings where higher-educated people were less likely to be physically active. ${ }^{8}$ Similarly, a systematic review identified the same pattern in seven South Asian countries, including Bangladesh. ${ }^{9}$ It may be possible that in Bangladesh and other developing countries, people with higher levels of education are mostly wealthy and do not require work-related PA. Besides, transport and leisure-time PA contribute much less to the overall PA among the Bangladeshi population, especially among the elderly. ${ }^{49} 50$ Another reason might be that, in Bangladesh, people with higher levels of education mostly live in urban settings. In our study, only $6 \%$ of rural and about $24 \%$ of non-slum urban participants had $\geq 10$ years of education, and the urban environment is not usually favourable for physical activities due to several reasons, including lack of infrastructure, lack of parks, use of motorised vehicles and dependence on labour-saving devices in household activities. ${ }^{50}$

Occupation and marital status were also associated with IPA among elderly people. Among both men and women, unemployed people or homemakers were more likely to be physically inactive. In Bangladesh, elderly people are more likely to be unemployed or retired. They are primarily dependent on their families for their livelihood, making them reluctant to perform PA. Therefore, initiatives should be taken to promote PA among elderly people who are unemployed or homemakers. The elderly persons without a spouse were less likely to be physically active, and the association is stronger among women than men. Similar findings were reported from the studies conducted in Malaysia and the USA. ${ }^{161}$ The familial responsibilities that come with marriage might explain why not-currently married people are less physically active.

Among modifiable factors of IPA, sedentary behaviour measured by higher sedentary time was associated with IPA in both sexes. A systematic review conducted by 
Open access

Table 5 Adjusted prevalence ratios (APR) of the factors of insufficient physical activity for men and women*

\begin{tabular}{|c|c|c|c|c|}
\hline \multirow[b]{2}{*}{ Variables } & \multicolumn{2}{|l|}{ Male } & \multicolumn{2}{|l|}{ Female } \\
\hline & APR $(95 \% \mathrm{Cl})$ & $P$ value & APR $(95 \% \mathrm{Cl})$ & $P$ value \\
\hline \multicolumn{5}{|l|}{ Age group (in years) } \\
\hline 60-69years & Ref. & & Ref. & \\
\hline 70-79years & 1.21 (1.10 to 1.34$)$ & $<0.001$ & 1.39 (1.26 to 1.54$)$ & $<0.001$ \\
\hline $80+$ years & 1.59 (1.41 to 1.79$)$ & $<0.001$ & 1.76 (1.57 to 1.97$)$ & $<0.001$ \\
\hline \multicolumn{5}{|l|}{ Place of residence } \\
\hline Rural & Ref. & & Ref. & \\
\hline Non-slum urban & 1.46 (1.31 to 1.63$)$ & $<0.001$ & 1.33 (1.19 to 1.48$)$ & $<0.001$ \\
\hline Slum & 1.49 (1.32 to 1.69$)$ & $<0.001$ & 1.10 (0.96 to 1.27$)$ & 0.174 \\
\hline \multicolumn{5}{|l|}{ Educational status } \\
\hline No formal education & Ref. & & Ref. & \\
\hline $1-5$ years & $1.02(0.89$ to 1.17$)$ & 0.739 & 0.99 (0.83 to 1.16$)$ & 0.860 \\
\hline $6-10$ years & 1.12 (1.01 to 1.25$)$ & 0.038 & 0.98 (0.86 to 1.12$)$ & 0.728 \\
\hline$>10$ years & 1.21 (1.06 to 1.37$)$ & 0.004 & 0.92 (0.69 to 1.23$)$ & 0.582 \\
\hline \multicolumn{5}{|l|}{ Occupation } \\
\hline Working & Ref. & & Ref. & \\
\hline Not working/homemaker & 1.91 (1.74 to 2.09 ) & $<0.001$ & 1.33 (1.12 to 1.58$)$ & 0.001 \\
\hline \multicolumn{5}{|l|}{ Household income } \\
\hline Lower income & Ref. & & Ref. & \\
\hline Higher income & NA & NA & 1.12 (1.02 to 1.23 ) & 0.019 \\
\hline \multicolumn{5}{|l|}{ Marital status } \\
\hline Currently married & Ref. & & & \\
\hline Others $\dagger$ & 1.14 (1.02 to 1.28$)$ & 0.022 & $1.4(1.22$ to 1.60$)$ & $<0.001$ \\
\hline \multicolumn{5}{|l|}{ Religion } \\
\hline Others $\ddagger$ & Ref. & & Ref. & \\
\hline Muslim & NA & NA & 1.07 (0.94 to 1.21$)$ & 0.315 \\
\hline \multicolumn{5}{|l|}{ Sedentary time } \\
\hline$\leq 7$ hours/day & Ref. & & Ref. & \\
\hline$>7$ hours/day & 1.37 (1.25 to 1.50$)$ & $<0.001$ & $1.40(1.28$ to 1.53$)$ & $<0.001$ \\
\hline \multicolumn{5}{|c|}{ Fruits and vegetables consumption } \\
\hline$\geq 5$ servings/day & Ref. & & Ref. & \\
\hline$<5$ servings/day & 1.25 (1.06 to 1.48$)$ & 0.007 & 1.21 (0.96 to 1.54$)$ & 0.110 \\
\hline \multicolumn{5}{|l|}{ Self-reported hypertension } \\
\hline No & Ref. & & Ref. & \\
\hline Yes & 1.15 (1.05 to 1.26$)$ & 0.002 & 1.14 (1.04 to 1.25$)$ & 0.006 \\
\hline \multicolumn{5}{|l|}{ Self-reported diabetes } \\
\hline No & Ref. & & Ref. & \\
\hline Yes & 1.06 (0.93 to 1.20$)$ & 0.424 & 1.18 (1.05 to 1.33$)$ & 0.005 \\
\hline \multicolumn{5}{|l|}{ Self-reported heart disease } \\
\hline No & Ref. & & Ref. & \\
\hline Yes & 1.06 (0.96 to 1.17$)$ & 0.247 & 1.09 (0.97 to 1.22$)$ & 0.139 \\
\hline \multicolumn{5}{|l|}{ Self-reported asthma } \\
\hline No & Ref. & & Ref. & \\
\hline Yes & 1.13 (1.03 to 1.24$)$ & 0.013 & 1.04 (0.92 to 1.17 ) & 0.548 \\
\hline
\end{tabular}




\begin{tabular}{|c|c|c|c|c|}
\hline \multirow[b]{2}{*}{ Variables } & \multicolumn{2}{|l|}{ Male } & \multicolumn{2}{|l|}{ Female } \\
\hline & APR $(95 \% \mathrm{Cl})$ & $P$ value & APR $(95 \% \mathrm{Cl})$ & $P$ value \\
\hline Male: $<90 \mathrm{~cm} /$ female: $<80 \mathrm{~cm}$ & Ref. & & Ref. & \\
\hline Male: $\geq 90 \mathrm{~cm} /$ female: $\geq 80 \mathrm{~cm}$ & 1.20 (1.08 to 1.33$)$ & $<0.001$ & 1.08 (0.98 to 1.19$)$ & 0.118 \\
\hline
\end{tabular}

*The outcome variable of Poisson regression analysis was insufficient physical activity $(\geq 150$ of physical activity per week=0, $<150$ min of physical activity per week=1).

†Never married, widows, divorced and separated.

$\ddagger$ Hindu, Christian, Buddhist and others.

NA, not applicable; Ref, reference category.

Mansoubi et alreported a similar association where sedentary time and PA. ${ }^{52}$ This relationship can be explained by the so-called displacement hypothesis-which suggests that sedentary time may displace PA. ${ }^{53}$ Objective monitoring of sedentary time is necessary to explore this association further. Interventions should be provided to balance sedentary time and PA to receive the full benefit of PA. We also observed that inadequate fruits and vegetable consumption was associated with IPA among elderly men. A study in Malaysia had similar findings where inadequate consumption of fruits and vegetable was significantly associated with a higher prevalence of IPA. ${ }^{16}$ Physically active people might consume more fruits and vegetable due to a relatively high awareness of NCD risk factors. In this population, a higher waist circumference or central obesity was associated with IPA among elderly men. This finding is supported by several studies in which PA was associated with lower waist circumference. ${ }^{54}$

In our study, self-reported hypertension in both sexes, self-reported diabetes in women, and self-reported asthma in men were associated with IPA. While the association between PA and NCDs is recognised, physical inactivity among people who already know their NCD status is somewhat related to a lack of knowledge and awareness. Vongpatanasin et al stated that hypertensive people are often reluctant to exercise out of fear of heart attack and stroke.$^{55}$ Elderly people with diabetes might be afraid of a hypoglycaemic episode during exercise. ${ }^{56}$ Similarly, people with asthma might also be reluctant to perform PA to avoid exacerbation. ${ }^{57}$ Proper health education and guidance are necessary to promote PA among people with existing NCDs.

\section{Strengths and limitations}

To the best of our knowledge, this is the first study in Bangladesh reporting national and regional estimates of prevalence and associated factors of IPA among elderly people. However, several limitations should be considered while interpreting the findings of the study. First, the measure of PA was subjective (self-reported) rather than objective, where a recall bias can compromise the study findings. Second, a modified version of the GPAQ questionnaire was used instead of the full version. Third, seven rural clusters were dropped due to administrative and financial constraints, which might affect the overall representativeness of the study. Finally, the lack of temporality of the associations between IPA and the factors was another limitation. We suggest further research to objectively measure the PA of elderly people and identify the determinants of IPA by conducting appropriately designed studies.

\section{Policy implication}

Our analysis showed that in Bangladesh, a large proportion of the elderly women and men is not performing the recommended level of PA. Besides, the prevalence of IPA is higher among certain classes of elderly people in the country. We observed that IPA is associated with several unmodifiable (age, place of residence, marital status, self-reported hypertension, self-reported diabetes, self-reported asthma) and modifiable factors (sedentary behaviour, inadequate fruits and vegetable consumption, higher waist circumference). The unmodifiable factors can be used to identify people with IPA. The modifiable factors can help us design appropriate interventions. As IPA has many adverse effects on overall health and increases the healthcare burden, the government of Bangladesh should take steps to increase PA in the elderly population. In Bangladesh, only $3 \%$ of people participate in recreational PA, suggesting that promoting recreational or leisure-time PA can reduce IPA. ${ }^{49}$ The lack of recreational PA is a concern for both the physical and mental well-being of the elderly population, and opportunities for elderly population specific recreational PA can be created. The government should establish more infrastructures such as parks, gymnasiums and PA clubs for the senior citizens. National awareness programmes can be taken with the help of religious institutions such as mosques, temples and churches. Besides, a national guideline for PA should be developed considering the cultural and socio-demographic situation of the country. Mass awareness, health education and counselling at the primary healthcare facilities and community level can also be effective.

\section{CONCLUSION}

In conclusion, IPA is highly prevalent among the elderly people of Bangladesh. It is a major concern, considering IPA is a crucial risk factor of NCD, and the elderly population has a higher likelihood of suffering from NCDs. The 
modifiable factors of IPA, such as sedentary behaviour, inadequate fruits and vegetable consumption and higher waist circumference, should be addressed through appropriate health education and counselling interventions. The non-modifiable factors can be used for identifying people at high risk of IPA.

Acknowledgements The authors thank all the study participants, research assistants, field supervisors, community leaders, local administrators and the Technical Advisory Committee for their continued support throughout this survey.

Contributors AAMH conceptualised and conducted the data analysis and drafted the initial manuscript. AAS, MHa, MMH, MSAK, MHo, MAU, SKS, SMMR, MMIB and DKM were involved in the conceptualisation and design of the survey, as well as reviewed and approved the final version of the manuscript. MSAK, AAMH and MHo administered the survey. MKM led the conceptualisation/design of the survey and supervision of data collection, critically reviewed and approved the final version of the manuscript.

Funding The study was funded by the National Nutrition Services (NNS), Institute of Public Health Nutrition, Ministry of Health and Family Welfare, Government of Bangladesh (Memo: 45.165.032.01.00.003.2016-325; Date: 10-12-2017). While drafting the manuscript, the salaries of some of the authors came from the funding by the National Institute for Health Research (NIHR), UK, and the Wellcome Trust, UK.

Competing interests Some of the representatives of the Ministry of Health and Family Welfare, who approved the funding of the study were involved with the Technical Advisory Group.

Patient and public involvement Patients and/or the public were not involved in the design, or conduct, or reporting, or dissemination plans of this research.

Patient consent for publication Not required.

Ethics approval The Institutional Review Board at the BRAC James P Grant School of Public Health, BRAC University, Dhaka, Bangladesh, has granted ethical approval for the FSNSP round 2018-19 (Ref: 2018-020-IR). We obtained written informed consent from the study participants.

Provenance and peer review Not commissioned; externally peer reviewed.

Data availability statement Data are available upon reasonable request. Data are available upon reasonable request. All such requests can be sent to the Institutional Review Board, BRAC James P Grant School of Public Health, BRAC University, Dhaka, Bangladesh, to the email address: irb-jpgsph@bracu.ac.bd.

Open access This is an open access article distributed in accordance with the Creative Commons Attribution Non Commercial (CC BY-NC 4.0) license, which permits others to distribute, remix, adapt, build upon this work non-commercially, and license their derivative works on different terms, provided the original work is properly cited, appropriate credit is given, any changes made indicated, and the use is non-commercial. See: http://creativecommons.org/licenses/by-nc/4.0/.

ORCID iD

Abu Abdullah Mohammad Hanif http://orcid.org/0000-0001-6274-5612

\section{REFERENCES}

1 World Health Organization. Global health risks: mortality and burden of disease attributable to selected major risks. Geneva, Switzerland: World Health Organization, 2009: 62.

2 Lee I-M, Shiroma EJ, Lobelo F, et al. Effect of physical inactivity on major non-communicable diseases worldwide: an analysis of burden of disease and life expectancy. Lancet 2012;380:219-29.

3 Strain T, Brage S, Sharp SJ, et al. Use of the prevented fraction for the population to determine deaths averted by existing prevalence of physical activity: a descriptive study. The Lancet Global Health 2020;8:e920-30

4 World Health Organisation. WHO guidelines on physical activity and sedentary behaviour. Geneva, Switzerland: World Health Organization, 2020.

5 Guthold R, Stevens GA, Riley LM, et al. Worldwide trends in insufficient physical activity from 2001 to 2016: a pooled analysis of 358 population-based surveys with 1.9 million participants. Lancet Glob Health 2018;6:e1077-86.

6 Riaz BK, Islam MZ, Islam ANMS, et al. Risk factors for noncommunicable diseases in Bangladesh: findings of the population- based cross-sectional national survey 2018. BMJ Open 2020;10:e041334

7 Zaman MM, Bhuiyan MR, Karim MN, et al. Clustering of noncommunicable diseases risk factors in Bangladeshi adults: an analysis of steps survey 2013. BMC Public Health 2015;15:659.

$8 \mathrm{Ng} \mathrm{N}$, Hakimi M, Van Minh H, et al. Prevalence of physical inactivity in nine rural indepth health and demographic surveillance systems in five Asian countries. Glob Health Action 2009;2:1985.

9 Ranasinghe CD, Ranasinghe P, Jayawardena R, et al. Physical activity patterns among South-Asian adults: a systematic review. Int $J$ Behav Nutr Phys Act 2013;10:116.

10 Sun F, Norman IJ, While AE. Physical activity in older people: a systematic review. BMC Public Health 2013;13:449.

11 Tu R, Li Y, Shen L, et al. The prevalence and influencing factors of physical activity and sedentary behaviour in the rural population in China: the Henan rural cohort study. BMJ Open . 2019;9:e029590.

12 Jahangir AR. Bangladesh faces a challenge to ensure welfare of its aging population. Inter Press Service [Internet], 2019. Available: http://www.ipsnews.net/2019/02/bangladesh-faces-challengeensure-welfare-aging-population/ [Accessed 21 Apr 2021].

13 Kabir ZN, Tishelman C, Agüero-Torres $\mathrm{H}$, et al. Gender and ruralurban differences in reported health status by older people in Bangladesh. Arch Gerontol Geriatr 2003;37:77-91.

14 Mridha MK, Hossain MM, Khan MSA, et al. Nutrition and health status of elderly people in Bangladesh: evidence from a nationwide survey. Curr Dev Nutr 2021;5:39.

15 World Health Organization. Physical activity [Internet], 2020. Available: https://www.who.int/news-room/fact-sheets/detail/ physical-activity [Accessed 21 Apr 2021].

16 Chan YY, Lim KK, Omar MA, et al. Prevalence and factors associated with physical inactivity among older adults in Malaysia: a cross-sectional study. Geriatr Gerontol Int 2020;20 Suppl 2:49-56.

17 Notthoff N, Reisch P, Gerstorf D. Individual characteristics and physical activity in older adults: a systematic review. Gerontology 2017;63:443-59.

18 The risks of rapid urbanization in developing countries [Internet]. Available: https://www.zurich.com/en/knowledge/topics/global-risks/ the-risks-of-rapid-urbanization-in-developing-countries [Accessed cited 2021 Jul 27]

19 Kuddus MA, Tynan E, McBryde E. Urbanization: a problem for the rich and the poor? Public Health Rev 2020;41:1.

20 Park S, Castaneda-Gameros D, Park S-Y, et al. Factors of physical activity and sedentary behavior in elderly Koreans. Am J Health Behav 2019;43:1040-9.

21 Chan YY, Sooryanarayana R, Mohamad Kasim N, et al. Prevalence and correlates of physical inactivity among older adults in Malaysia: findings from the National health and morbidity survey (NHMS) 2015. Arch Gerontol Geriatr 2019;81:74-83.

22 Non-communicable Disease Control Programme, Directorate General of Health Services. Multi-sectoral action plan for prevention and control of non-communicable diseases 2018-2025. Dhaka, 2018.

23 Mridha MK, Hossain MM, Khan MSA, et al. Prevalence and associated factors of depression among adolescent boys and girls in Bangladesh: findings from a nationwide survey. BMJ Open . 2021;11:e038954.

24 Hossain MM, Akter F, Hanif AAM, et al. Prevalence of and factors associated with insufficient physical activity among adolescents: evidence from a nationwide survey in Bangladesh. J Biosoc Sci 2021:1-14

25 Hanif AAM, Shamim AA, Hossain MM, et al. Gender-Specific prevalence and associated factors of hypertension among elderly Bangladeshi people: findings from a nationally representative crosssectional survey. BMJ Open 2021;11:e038326.

26 World Health Organization. Global recommendations on physical activity for health. [Internet], 2010. Available: http://www.ncbi.nlm. nih.gov/books/NBK305057/ [Accessed 24 Jan 2020].

27 Mumu SJ, Ali L, Barnett A, et al. Validity of the global physical activity questionnaire (GPAQ) in Bangladesh. BMC Public Health 2017; $17: 650$.

28 Hanif AAM, Hasan M, Khan MSA, et al. Ten-years cardiovascular risk among Bangladeshi population using non-laboratory-based risk chart of the world Health organization: findings from a nationally representative survey. PLoS One 2021;16:e0251967.

29 Martinez BAF, Leotti VB, Silva GdeSE, et al. Odds ratio or prevalence ratio? an overview of reported statistical methods and appropriateness of interpretations in cross-sectional studies with dichotomous outcomes in veterinary medicine. Front Vet Sci 2017:4:193. 
30 Barros AJD, Hirakata VN. Alternatives for logistic regression in crosssectional studies: an empirical comparison of models that directly estimate the prevalence ratio. BMC Med Res Methodol 2003;3:21.

31 Zocchetti C, Consonni D, Bertazzi PA. Relationship between prevalence rate ratios and odds ratios in cross-sectional studies. Int $J$ Epidemiol 1997;26:220-3.

32 Maldonado G, Greenland S. Simulation study of confounderselection strategies. Am J Epidemiol 1993;138:923-36.

33 Uddin R, Hasan M, Saif-Ur-Rahman KM, et al. Physical activity and sedentary behaviour in Bangladesh: a systematic scoping review. Public Health 2020;179:147-59.

34 The World Bank. Life expectancy at birth, total (years) - Bangladesh Data [Internet], 2021. Available: https://data.worldbank.org/indicator/ SP.DYN.LE00.IN?locations=BD [Accessed 03 May 2021].

35 Aslesh OP, Mayamol P, Suma RK, et al. Level of physical activity in population aged 16 to 65 years in rural Kerala, India. Asia Pac J Public Health 2016;28:53S-61.

36 Devamani C, Oommen A, Mini G. Levels of physical inactivity in rural and urban Tamil Nadu, India: a cross-sectional study. J Clin Prev Cardiol 2019;8:13-17.

37 JS Consultancy Services. Non-Communicable Disease Risk Factor Survey 2018 - Country Report for Afghanistan. Kabul, Afghanistan: JS Consultancy Services, 2020.

38 Pakistan Health Research Council. NON-COMMUNICABLE DISEASES RISK FACTORS SURVEY 2014-15 - PAKISTAN. Islamabad, Pakistan: Pakistan Health Research Council, 2016.

39 Dhimal M, Bista B, Bhattarai S. Noncommunicable disease risk factors: steps survey Nepal 2019. Kahtmandu, Nepal: Nepal Health Research Council (NHRC), 2020.

40 Dorji T, Dukpa W, Doma K, et al. National survey for noncommunicable disease risk factors and mental health using WHO STEPS approach in Bhutan-2014. New Delhi, India: World Health Organization, 2015.

41 Ministry of Health, Nutrition and Indigenous Medicine. Non communicable disease risk factor survey Sri Lanka 2015, 2015.

42 Organization WH. WHO STEPS survey on risk factors for noncommunicable diseases, Maldives, 2011. WHO Regional Office for South-East Asia, 2014.

43 Keadle SK, McKinnon R, Graubard BI, et al. Prevalence and trends in physical activity among older adults in the United States: a comparison across three national surveys. Prev Med 2016;89:37-43.

44 Australian Institute of Health and Welfare. Insufficient physical activity [Internet]. Available: https://www.aihw.gov.au/reports/ australias-health/insufficient-physical-activity [Accessed $24 \mathrm{Ju}$ 2021].
45 Sport England. Active Lives Adult Survey November 2019/20 Report [Internet], 2021. Available: https://www.sportengland.org/know-youraudience/data/active-lives?section=access_the_reports [Accessed 24 Jul 2021].

46 Gomes M, Figueiredo D, Teixeira L, et al. Physical inactivity among older adults across Europe based on the share database. Age Ageing 2017;46:71-7.

47 Cunningham $\mathrm{C}$, O' Sullivan R. Why physical activity matters for older adults in a time of pandemic. Eur Rev Aging Phys Act 2020;17:16.

48 The World Bank. Urban population (\% of total population) Bangladesh | Data [Internet], 2021. Available: https://data.worldbank. org/indicator/SP.URB.TOTL.IN.ZS?end=2019\&locations=BD\&start= 1960\&view $=$ chart [Accessed 04 May 2021].

49 Moniruzzaman M, Mostafa Zaman M, Islalm MS, et al. Physical activity levels in Bangladeshi adults: results from steps survey 2010. Public Health 2016;137:131-8.

50 Moniruzzaman M, Ahmed MSAM, Zaman MM. Physical activity levels and associated socio-demographic factors in Bangladeshi adults: a cross-sectional study. BMC Public Health 2017;17:1-8.

51 Pettee KK, Brach JS, Kriska AM, et al. Influence of marital status on physical activity levels among older adults. Med Sci Sports Exerc 2006;38:541-6.

52 Mansoubi M, Pearson N, Biddle SJH, et al. The relationship between sedentary behaviour and physical activity in adults: a systematic review. Prev Med 2014;69:28-35

53 MUTZ DC, ROBERTS DF, van VDP. Reconsidering the Displacement Hypothesis: Television's Influence on Children's Time Use. Communication Research 1993;20:51-75.

$54 \mathrm{Du} \mathrm{H}$, Bennett D, Li L, et al. Physical activity and sedentary leisure time and their associations with BMI, waist circumference, and percentage body fat in 0.5 million adults: the China Kadoorie Biobank study. Am J Clin Nutr 2013;97:487-96.

55 ScienceDaily. Dangerous blood pressure increases during exercise can be blocked, researchers find [Internet]. Available: https://www. sciencedaily.com/releases/2011/04/110404173250.htm [Accessed 04 May 2021].

56 BMJ. Fear of hypoglycaemia is the greatest barrier to exercise in type 1 diabetics: What health professionals need to know [Internet]. BJSM blog - social media's leading SEM voice, 2015. Available: https://blogs.bmj.com/bjsm/2015/11/28/6552/ [Accessed 04 May 2021].

57 Panagiotou M, Koulouris NG, Rovina N. Physical activity: a missing link in asthma care. J Clin Med 2020;9:706. 